\title{
HACIA LA EDUCACIÓN SECUNDARIA OBLIGATORIA. NOTAS DEL PROCESO EN LA REPÚBLICA ARGENTINA
}

TOWARDS COMPULSORY HIGH SCHOOL EDUCATION - NOTES OF THE PROCESS IN THE ARGENTINE REPUBLIC

\section{Volumen 13, Número 2 Mayo - Agosto}

pp. 1-29

Este número se publicó el 30 de mayo de 2013

\author{
Horacio Ferreyra \\ Silvia Vidales \\ Marta Kowadlo \\ Laura Bono \\ colaboración de Olga Bonetti
}

Revista indizada en REDALYC, SCIELO

Revista distribuida en las bases de datos:

CATÁLOGO DE LATINDEX, IRESIE, CLASE, DIALNET, DOAJ, E-REVIST@S, SHERPA/ROMEO, QUALIS

Revista registrada en los directorios:

ULRICH'S, REDIE, RINACE, OEI, MAESTROTECA, PREAL, CLASCO 


\title{
HACIA LA EDUCACIÓN SECUNDARIA OBLIGATORIA. NOTAS DEL PROCESO EN LA REPÚBLICA ARGENTINA TOWARDS COMPULSORY HIGH SCHOOL EDUCATION - NOTES OF THE PROCESS IN THE ARGENTINE REPUBLIC
}

\author{
Horacio Ferreyra $^{1}$ \\ Silvia Vidales ${ }^{2}$ \\ Marta Kowadlo ${ }^{3}$ \\ Laura Bono ${ }^{4}$ \\ con la colaboración de Olga Bonetti ${ }^{5}$
}

Resumen: El presente ensayo se propone revisar y discutir las transformaciones por las que está atravesando la Educación Media/Secundaria en Argentina, en el contexto de un período de transición y resignificación, donde conviven factores vinculados a los dos últimos marcos normativos: la Ley Federal de Educación № 24.195 y la Ley de Educación

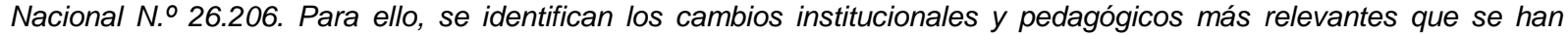
suscitado en el lapso que abarca desde el año 2001 hasta la fecha y se reflexiona sobre ellos. Posteriormente, se focaliza el análisis en torno a los logros alcanzados y los desafíos pendientes. Se concluye que -bajo el denominador común de un modelo de trabajo participativo- existe continuidad en las líneas de trabajo, aunque cabe reconocer que la situación en el país es diversa y que restan acciones a concretar y aspectos a fortalecer.

Palabras clave: POLÍTICA EDUCATIVA, EDUCACIÓN MEDIA, EDUCACIÓN SECUNDARIA, NORMATIVA, OBLIGATORIEDAD, ACUERDOS FEDERALES, PROGRAMAS, ARGENTINA

\begin{abstract}
The aim of the present essay is to review and discuss the transformations High School Education in Argentina is going through, in the context of a period of transition/redefinition in which factors related to the two latest normative frameworks (Federal Law of Education number 24.195 and Law of National Education number 26.206) coexist. Thus, the most relevant institutional and pedagogical changes that have taken place in the period ranging from 2001 up to the present are identified and then reflected upon. Then, we focus on the analysis about the achieved aims and the pending challenges. We conclude that - under a common denominator of a participatory work model - there is a continuity in the work cores, although we have to acknowledge the fact that the situation in the country is diverse and that there are still some actions to do and some aspects to reinforce.
\end{abstract}

Key words: EDUCATIONAL POLICY, HIGH SCHOOL EDUCATION, LAW, COMPULSORY, FEDERAL AGREEMENTS, SYLLABI, ARGENTINA

\footnotetext{
${ }^{1}$ Docente e Investigador de la Universidad Católica de Córdoba, Argentina. Subsecretario de Estado de Promoción de Igualdad y Calidad Educativa del Ministerio de Educación, Córdoba. Doctor en Educación (Universidad Católica de Córdoba UCC). Dirección electrónica: hferreyra@coopmorteros.com.ar

${ }^{2}$ Coordinadora de Gestión Curricular y Referente del Plan Provincial de Lectura de la SEPlyCE, del Ministerio de Educación, Córdoba. Profesora y Licenciada en Letras Modernas (UNC), con estudios de Posgrado en Enseñanza en Educación Superior (Universidad Diego Portales, Chile).Dirección electrónica: silvidales@gmail.com

${ }^{3}$ Referente Curricular en Educación Artística en la SEPIyCE, Ministerio de Educación, Córdoba. Profesora Adjunta de Teorías Psicológicas de Aprendizaje en la Facultad de Educación de la Universidad Católica de Córdoba, Argentina. Licenciada y Profesora en Ciencias de la Educación (UCC). Dirección electrónica: marta kow@hotmail.com

${ }^{4}$ Docente de la Universidad de Chilecito (La Rioja, Argentina) y de la Fundación Hombre Libre. Referente Curricular en Ciencias Naturales de la Subsecretaría de Estado de Promoción de Igualdad y Calidad Educativa (SEPlyCE), del Ministerio de Educación de la Provincia de Córdoba. Dirección electrónica: bonolaura@hotmail.com

${ }^{5}$ Decana de la Facultad de Educación, Universidad Católica de Córdoba, Argentina. Directora de la Revista Diálogos Pedagógicos de la misma universidad. Licenciada en Ciencias de la Educación (UCC). Especialista en Gestión y Conducción del Sistema Educativo y sus Instituciones (FLACSO Argentina). Dirección electrónica: olgacbonetti@gmail.com
}

Ensayo recibido: 23 de octubre, 2012

Aprobado: 22 de febrero, 2013 


\section{Introducción}

La Educación Media/Secundaria ${ }^{6}$ en el Sistema Educativo Argentino es un trayecto formativo que involucra a sujetos, saberes y prácticas, y cuya configuración sociohistórica ha colocado en tensión diversos aspectos de su disposición interna y, al mismo tiempo, suscitado diferentes instancias de re-conceptualización y re-definición de sus objetivos y alcances, a partir de múltiples reformas y/o transformaciones, en el intento de responder a los requerimientos de una sociedad en permanente cambio.

Atendiendo a este contexto, el Grupo de Estudio de Educación Secundaria de la Facultad de Educación de la Universidad Católica de Córdoba, Argentina, del cual formamos parte, realizó un estudio de tipo descriptivo (cuanticualitativo ${ }^{7}$ ) sobre la Educación Secundaria en la Argentina (sentido, contexto y evolución) en el período correspondiente a la primera década del presente siglo. La investigación se planteó los siguientes objetivos:

- Describir las transformaciones por las que ha transitado la Educación Media/Secundaria en el contexto latinoamericano y mundial.

- Relevar los aportes de investigaciones destacadas, a fin de dar cuenta de una aproximación al estado de la producción de conocimiento en torno a los problemas y propuestas vinculados con este nivel educativo.

- Analizar los logros y avances, así como las tensiones, problemáticas y temas críticos emergentes que se pueden constatar en los diversos procesos de reforma y transformación de la Educación Media/Secundaria en Argentina.

- Recuperar experiencias institucionales y curriculares que logran dar cuenta de buenas prácticas en sus respectivos contextos, a los fines de delinear y sistematizar los factores que promueven la mejora.

6 En este texto nos referiremos a la Educación Secundaria o Media de manera indistinta, porque la entendemos, en su conjunto, como aquel eslabón del sistema dirigido al grupo de edad de 11/12 a 17/18 años (Nivel 2: Primer Ciclo de Educación Secundaria, o bien, Segundo Ciclo de Educación Básica "Secundaria Básica" y el Nivel 3: Segundo Ciclo de la Educación Secundaria "Secundaria Superior" -Clasificación Internacional Normalizada de la Educación -Unesco 1997, revisada en 2011-).

7 La recolección de datos relevantes se llevó a cabo mediante la combinación y confrontación de diversas fuentes (primarias y secundarias) procedentes de distintos actores y agencias de producción del conocimiento (del ámbito estatal y/o privado). Para ello, se realizó investigación bibliográfica, un trabajo de campo -aplicando variadas técnicas (análisis documental, observaciones no participantes, entrevistas semi-estructuradas y en profundidad a informantes claves, entrevistas grupales)- y se organizó un seminario taller con la participación de directivos, docentes, técnicos, funcionarios, expertos y los integrantes del grupo de investigación. Las categorías de análisis que guiaron el trabajo documental y de campo fueron currículum, saberes y prácticas en contexto y trayectoria escolar de los estudiantes (sentido), ambiente y clima institucional (contexto), desarrollo profesional docente y relaciones con la comunidad (evolución). 
Los resultados que abordamos en este ensayo ${ }^{8}$ se organizan en un recorrido que pretende, a través de los distintos apartados, revisar y discutir algunas de las transformaciones más relevantes que se han suscitado en la Educación Secundaria argentina, en el marco de la Ley de Educación Federal (del año 1993) y la Ley de Educación Nacional (del año 2006), así como identificar avances y plantear algunos desafíos pendientes.

\section{Proposición: Conocer para transformar}

La educación, como proceso social que se desarrolla en tiempos históricos, se sostiene en los saberes, prácticas y creencias acumulados en el pasado, las innovaciones del presente y las demandas que impone el futuro, para hacer posible la transformación dinámica, creativa y permanente entre lo que fue, lo que es, lo que está siendo y lo que será. Así, pasado, presente y futuro se integran en el proceso de cambio educativo, resignificándolo.

Por su parte, el sistema educativo es el resultado de un proceso sociopolítico e ideológico formulado en un contexto témporo-espacial determinado y a la vez histórico, en el que se conjugan tradiciones e innovaciones. Tradición, para dar continuidad a las ideas y obras iniciadas en el pasado e innovación creativa, para renovar la propuesta y dar respuesta a las demandas formativas de la sociedad.

En Argentina, en el contexto latinoamericano, la Educación Media/Secundaria se ha constituido, en las últimas décadas, en un trayecto educativo complejo que, precisamente por serlo, ha sido objeto no solo de numerosos debates, sino, también, de múltiples proyectos de transformación y/o reforma. Por ello, entendemos que es necesario profundizar en su conocimiento para poder formular propuestas de cambio y mejora que nos permitan construir para la Educación Secundaria en Argentina -desde el discurso y a través de la acción socialmente comprometida- el mejor de los futuros posibles.

\footnotetext{
8 Para la elaboración de este ensayo, se retoman ideas desarrolladas in extenso en Ferreyra (coord.), 2012.
} 


\section{Argumentos para la discusión}

\subsection{La Educación Media/Secundaria en la Argentina}

La Educación Media/Secundaria en la Argentina está atravesando un período que algunos autores consideran de transición y otros de resignificación, en el cual conviven factores vinculados a los dos últimos marcos normativos: la Ley Federal de Educación №24.195 y la Ley de Educación Nacional №26.206. Por ello, y en el contexto del debate planteado en este estudio, consideramos relevante una revisión de algunas de las transformaciones que se han suscitado desde el 2001 hasta la fecha.

\subsubsection{La Educación Media/Secundaria en el marco de la Ley Federal de Educación} № 24.195/93

En abril del año 1993, y teniendo en cuenta las conclusiones del Congreso Pedagógico Nacional (1986-1988) ${ }^{9}$, se sancionó la Ley Federal de Educación №24.19510, como expresión de una nueva posición en la educación argentina. En ella se establecen la prioridad y la urgencia de impulsar nuevas políticas y estrategias en educación, con el propósito de universalizar el acceso, fomentar la equidad y propiciar la calidad de los aprendizajes.

A partir de la Ley Federal de Educación, la escolaridad obligatoria se prolonga de 7 a 10 años y se modifica la estructura del Sistema Educativo Argentino, que queda conformado por el Nivel Inicial (de un año de duración), la Educación General Básica (EGB, organizada en tres ciclos de 3 años cada uno: EGB1, EGB2 y EGB3) y la Educación Polimodal (EP, un ciclo que comprendía, como mínimo, los tres últimos años de la escuela secundaria ${ }^{11}$ ); se implementan, además, los Trayectos Técnicos Profesionales (TTP) ${ }^{12}$. De igual manera, se propicia un nuevo modelo de organización y gestión, y se promueve una transformación curricular para favorecer la actualización y la regionalización de los contenidos.

Esta fue la primera ley federal que intentó ordenar todos los niveles del sistema educativo, pero especialmente el Medio/Secundario, que -por primera vez- es abordado

\footnotetext{
9 Ley 23114-Congreso Pedagógico Nacional.

${ }^{10}$ Cabe destacar que en 1995 se sanciona, además, la Ley de Educación Superior № 24.521.

${ }^{11}$ La cantidad y duración en años de los ciclos de la EGB no estaban previstas en la Ley Federal. Los tres ciclos de tres años cada uno fueron acordados posteriormente -no por unanimidad- en el seno del Consejo Federal de Cultura y Educación (CFCyE) (sobre este Consejo, ver nota 11).

${ }^{12}$ La Ley Federal no contemplaba los TTP; su implementación también fue acordada posteriormente en el seno del CFCyE.
} 
jurídicamente en forma integral (Gallart, 2006). A pocos años de su sanción, Albergucci (1996) sostenía:

Esta ley marco del sistema educativo ofrece un ordenamiento para la transformación. Es una ley general porque comprende todos los niveles y ciclos, todos los regímenes especiales e incluso la educación no formal. Es una ley básica porque plantea los lineamientos para las transformaciones educativas. Es una ley nacional porque comprende y obliga a todas las provincias para la unidad nacional del sistema. Es una Ley federal porque proclama esa unidad desde las diversidades culturales, regionales y jurisdiccionales. Hay aportes sobre política educativa nacional, función del Estado, promoción y evaluación de la calidad educativa, jerarquización del rol y función del docente; organización curricular; organización escolar (p.37).

Mientras el Tercer Ciclo de la Educación General Básica (EGB 3) propició la consolidación de un núcleo de competencias básicas, la Educación Polimodal (EP) procuró una formación general y orientada hacia amplios campos de conocimiento a través de una organización en Modalidades ${ }^{13}$. Por su parte, los Trayectos Técnico Profesionales (TTP), Itinerario Profesional (IF) y Formación Profesional (FP) fueron opciones de formación, más o menos prolongadas en el tiempo, que se vincularon con un área ocupacional y apuntaron a desarrollar competencias específicas y de iniciación en la especialización, evitando una formación centrada en un puesto laboral, debido a las características cambiantes del mercado de trabajo (Peretti, Ferreyra y Carandino, 2001-2003).

Simultáneamente a los cambios de estructura, la Ley Federal de Educación estableció la elaboración de los Contenidos Básicos Comunes (CBC) para todo el territorio nacional con el fin de que cada jurisdicción construyera su Diseño Curricular Jurisdiccional (DCJ). Fueron elaborados por especialistas, prescribiendo inicialmente un conjunto de saberes mínimos para todos los argentinos (que luego se consideraron de máxima), con orientaciones y sugerencias abiertas a la redefinición en el nivel provincial y en el nivel escolar (Ferreyra, 2006).

\footnotetext{
${ }^{13}$ La Educación Polimodal se organizó a partir de cinco modalidades: Producción de Bienes y Servicios, Economía y Gestión de las Organizaciones, Humanidades y Ciencias Sociales, Ciencias Naturales y Comunicación, Arte y Diseño.
} 
En las provincias, las traducciones de los CBC que se realizaron para la EGB 3 acrecentaron la dispersión, puesto que la mayoría ya tenía definida su propuesta para cuando estuvieron terminados (Fernández, Finocchio y Fumagalli, en Braslavsky org., 2001). Además, algunas de las dificultades de los nuevos diseños también se explican por la distancia existente entre los programas de formación de los Institutos de Formación Docente y el currículum a enseñar en las escuelas.

Transcurridos diez años de la sanción de la Ley Federal, se constató que coexistían en el país aproximadamente veinticuatro (24) sistemas educativos, entre los que se reconocen aquellos que implementaron con notables diferencias lo dispuesto en dicha legislación (diversidad de estructuras curriculares tanto en EGB 3 como en Polimodal, en cuanto a cantidad de espacios curriculares, carga horaria asignada a cada uno de ellos, inclusión de espacios de definición institucional, entre otros), los que mantuvieron las estructuras anteriores (Primaria y Secundaria) ${ }^{14}$, los que aplicaron la reforma a escala reducida ${ }^{15}$ y otra en la que coexistían estructuras diferentes ${ }^{16}$. Todo esto ponía en evidencia una suerte de "anarquía jurisdiccional" en razón de las notables diferencias de implementación entre las distintas provincias (Ferreyra, 2006). De igual manera, la dispersión curricular fue correlativa de una gran diversificación de las regulaciones y las prácticas de evaluación y promoción de los estudiantes, ya que las distintas normas provinciales en la materia fueron sumamente divergentes entre sí y laxas en cuanto a los saberes que deberían evaluarse y acreditarse.

Así, tal como se señala en un documento de Argentina, Ministerio de Educación, Ciencia y Tecnología, DINIECE (2007), se constata una paradoja:

la primera norma que dio organicidad a la escuela secundaria la dividió en dos niveles educativos, y propició -en el transcurso de su implementación- una gran diversidad de modelos organizativos institucionales (...). El saldo de este proceso llevó a una diversificación de estructuras académicas, curriculares e institucionales, lo cual implicó un desdibujamiento del sistema educativo en general y de la escuela secundaria en particular... (p.7).

\footnotetext{
${ }^{14}$ Ciudad Autónoma de Buenos Aires, Río Negro y Neuquén.

${ }^{15}$ Chaco, Jujuy, Santiago del Estero.

${ }^{16}$ Entre Ríos.
} 
Si bien a 10 años de la sanción de esta Ley se comenzaría a cuestionar que muchos de sus postulados no se habían concretado por fallas en su implementación, lo cierto es que la transformación educativa puesta en marcha en 1993 modificó las estructuras legales, organizativas, académicas y curriculares, según nuevas opciones político-educativas, económicas y socioculturales, afectando los ejes fundantes del modelo escolar surgido en el siglo $\mathrm{XIX}^{17}$.

El repliegue del Estado, atemperado con la promesa de alcanzar una mayor descentralización ${ }^{18}$, desburocratización y democratización del Sistema Educativo sustentó la transferencia de los servicios educativos a las provincias, pero este proceso no fue ordenado y coherente, sino que, en la práctica, significó que los cambios en la estructura y modalidades del sistema educativo -en aquellas provincias donde se implementó- estuviera muy lejos de favorecer la regionalización, conformándose así un mapa caóticamente heterogéneo, dispar e inequitativo. Dada la desigualdad de condiciones en que se encontraban las diferentes jurisdicciones provinciales, no fue tampoco posible garantizar la igualdad de oportunidades por la que bregaba la Ley ${ }^{19}$.

Como resultados positivos, pueden señalarse una mayor incorporación de estudiantes en los primeros años de la Educación Secundaria y el inicio de los debates sobre el carácter selectivo y excluyente del Polimodal. También se puede observar una tendencia a otorgar mayores márgenes de decisión a los docentes, que si bien supuso una democratización de las definiciones pedagógicas también resultó desconcertante y el mercado editorial terminó reemplazando la pedagogía estatal. Según Veleda, Rivas y Mezzadra (2011), "la extensión progresiva de la educación secundaria como un derecho universal también puede ser

\footnotetext{
${ }^{17}$ Para ampliar, véase Ávila Paz, Bonetti y Chiavaro, 2003.

${ }^{18}$ Cabe destacar que si bien la descentralización de la educación se realizó en más de una etapa, desde el comienzo mismo se puso en funcionamiento un ámbito de reunión de las diversas jurisdicciones, el Consejo Federal de Cultura y Educación. Este Consejo nace en el año 1972, pensado como ámbito de coordinación, en orden a favorecer la acción conjunta de la Nación y las provincias mediante el Decreto Ley № 19.682, que fue modificado durante la dictadura militar (Decreto Ley № 22.047). Actualmente, es el organismo de acuerdo y concertación de la política educativa nacional para asegurar la unidad y articulación del Sistema Educativo Nacional. Su presidente es el Ministro de Educación de la Nación y se encuentra a su vez integrado por la máxima autoridad educativa de cada jurisdicción y tres representantes del Consejo de Universidades.

${ }^{19}$ Es de destacar que desde 1990, y hasta la sanción de la Ley de Educación Nacional № 26.206, según señalan Veleda, Rivas y Mezzadra (2011), "Los dispositivos de la política educativa se transforman y toman formatos materiales y modalidades distributivas: comedores, becas, equipamiento y financiamiento de proyectos en escuelas vulnerables.Se modifica la noción de igualdad y se impone el concepto de equidad: dar más a los que menos tienen, con un tratamiento diferenciado de las escuelas más pobres. La equidad se asume como estrategia para lograr mayor igualdad..." (p.28).
} 
considerada como uno de los grandes valores de esta etapa..." (p.31), conquista que se profundizará con la sanción de la Ley de Educación Nacional de 2006.

\subsubsection{La Ley de Educación Nacional № 26.206, un nuevo marco normativo para el cambio de la Educación Secundaria}

A partir del análisis de la crisis del sistema educativo, se iniciaron acciones tendientes a revertir la situación anárquica y propiciar el avance hacia un nuevo marco normativo. En el año 2005 se sancionaron la Ley de Educación Técnico Profesional № 26.058 y la Ley de Financiamiento Educativo № 26.075. Además, con el propósito de derogar la Ley Federal de Educación, durante 2006 se impulsó un debate con el objetivo de analizar y consensuar una nueva norma y, a fines de ese año, se sancionó la Ley de Educación Nacional № 26.206, que regula el ejercicio del derecho de enseñar y aprender consagrado por el artículo 14 de la Constitución Nacional y los tratados internacionales incorporados a ella (Art.1) y establece que la educación y el conocimiento son un bien público y un derecho personal y social, garantizados por el Estado (Art.2) y que la educación es una prioridad nacional y se constituye en política de Estado para construir una sociedad justa, reafirmar la soberanía e identidad nacional, profundizar el ejercicio de la ciudadanía democrática, respetar los derechos humanos y libertades fundamentales y fortalecer el desarrollo económico-social de la Nación (Art.3). En el mismo sentido, afirma la responsabilidad principal e indelegable [por parte del Estado] de proveer una educación integral, permanente y de calidad para todos los habitantes de la Nación y garantizar la igualdad, gratuidad y equidad en el ejercicio de este derecho, con la participación de las organizaciones sociales y las familias (Art.4) ${ }^{20}$.

Esta nueva legislación implica un profundo cambio en la concepción políticopedagógica de la Educación Secundaria. Según lo establecen los artículos 29 y 30 de la Ley de Educación Nacional № 26.206:

\footnotetext{
${ }^{20}$ Anteceden las Leyes de Garantía del salario docente y ciento ochenta días de clase (Ley N. 25.864, sancionada en diciembre de 2003), Fondo Nacional de Incentivo Docente (Ley N.․ 25.919, sancionada en agosto de 2004), Protección Integral de los Derechos de las Niñas, Niños y Adolescentes (Ley N.․․ 26.061 sancionada el 26 de octubre de 2005) y Educación Sexual Integral (Ley N. 26.150, sancionada en octubre de 2006). Se agregan, posteriormente, la Ley de Promoción y Regulación de los Centros de Desarrollo Infantil (Ley N. 26.233, sancionada en marzo de 2007), la Ley de Prohibición del Trabajo Infantil y Protección del Trabajo Adolescente (Ley N.․ 26.930, sancionada el 4 de junio de 2008) y la Ley N.o 26.427 de Pasantías Educativas, sancionada en noviembre de 2008 (Reglamentada por Resolución Conjunta entre el Ministerio de Educación y el de Trabajo, Empleo y Seguridad Social de la Nación N. 825/2009 y № 338/2009). Respecto de la cantidad de días de clase, mediante Resolución №165/11 del CFE, se establece que los calendarios escolares del año 2012 prevean 190 días de clase.
} 
La Educación Secundaria es obligatoria y constituye una unidad pedagógica y organizativa destinada a los/as adolescentes y jóvenes que hayan cumplido con el nivel de Educación Primaria (...) tiene la finalidad de habilitar a los/las adolescentes y jóvenes para el ejercicio pleno de la ciudadanía, para el trabajo y para la continuación de estudios.

La nueva concepción sitúa a la Educación Secundaria como el espacio de la escolaridad que tiene como objetivo fundamental lograr la inclusión, permanencia, progreso, promoción y egreso con calidad de todos/as los adolescentes y jóvenes del país, para lo cual resulta indispensable realizar una propuesta de enseñanza distinta, centrada en quienes aprenden desde una perspectiva situada. La sanción de la Ley de Educación Nacional №26.206 - sostienen Veleda, Rivas y Mezzadra (2011), "constituye una pieza clave para consolidar un sistema educativo que amplíe las oportunidades educativas de los sectores más desfavorecidos y fortalezca la integración social ante las difíciles y dispares condiciones de vida de la población ${ }^{21 "}$ (p.14).

Si bien la Ley Federal de Educación había avanzado en garantizar ciertos derechos a través de la extensión de la obligatoriedad escolar, la LEN lo hace en cuanto a la protección del derecho a la educación, definiéndola como un derecho personal y social, ampliando la obligatoriedad. Se comienza, de este modo, a transitar el camino desde la incorporación a la inclusión educativa (Sañudo Guerra, 2007).

En la dimensión curricular, los saberes fundamentales aparecen definidos a través de los Núcleos de Aprendizajes Prioritarios (NAP), como conjunto de saberes y capacidades centrales, relevantes y significativas que se incorporan como objetos de enseñanza, con la intención de promover la integración del Sistema Educativo Nacional y superar la referida fragmentación (Resolución del CFCYE N 214/04). En el Anexo I de dicha Resolución se expresa:

Esto implica para la escuela potenciar su función igualadora desde lo que sabe, puede y debe hacer como institución especializada en la enseñanza y el aprendizaje. Implica además, renovar el compromiso con el aprendizaje de los niños, jóvenes y adultos con

\footnotetext{
${ }^{21}$ Los autores destacan también la importancia de la Ley de Financiamiento Educativo (N. $\left.{ }^{\circ} 26.075\right)$ de 2005, en tanto afianzó la institucionalidad del financiamiento del sector e impulsó un importante y sostenido aumento de la inversión.
} 
preocupación por la calidad de la enseñanza impartida y por los resultados alcanzados (p.1).

La construcción de los NAP se ha ido concretando mediante un proceso que se inició antes de la sanción de la LEN y que aún hoy continúa. La elaboración de los NAP de Educación Inicial, Primaria y Secundaria está a cargo de equipos federales ${ }^{22}$ conformados por representantes políticos, técnicos, supervisores y docentes de las provincias argentinas y de la Ciudad Autónoma de Buenos Aires, y por los técnicos del Ministerio de Educación de la Nación, y son aprobados por las autoridades educativas de todas las Jurisdicciones en el seno del Consejo Federal de Educación ${ }^{23}$.

La definición de los NAP implica poner en directa relación el currículum y la enseñanza. Desde la misma Resolución del CFCYE que les da origen, se señala que la Propuesta "Procura asegurar una base de unidad al sistema atendiendo a la diversidad de sus realidades y generar intervenciones que constituyan ayudas a la tarea del aula" (Anexo I. Resolución CFCYE N 214/04, p.3). En este sentido, y tal como se hace explícito en un informe del Ministerio de Educación, Ciencia y Tecnología (2007), la Dirección Nacional de Gestión Curricular junto a la Subsecretaría de Equidad y Calidad definieron y llevaron a cabo un conjunto de tareas orientadas a reponer la centralidad de la discusión sobre la enseñanza en las políticas educativas, como condición necesaria y decisiva para la construcción de un horizonte de igualdad; planificar y desarrollar encuentros nacionales y regionales para la discusión colectiva sobre la enseñanza; producir materiales de apoyo al desarrollo curricular; diseñar y poner en práctica proyectos de atención focalizada a problemas de enseñanza específicos.

Con el fin de dar cuenta de los fundamentos en los que se sostienen estas acciones, que evidencian la importancia creciente de las políticas de enseñanza, en ese Informe se expresa:

Efectivamente, si la pobreza y la exclusión social demarcaron un espacio de profunda desigualdad para la tarea de los docentes y para las trayectorias escolares de niñas, niños y jóvenes de todo el país, la definición de políticas de enseñanza orientadas a la

\footnotetext{
${ }^{22}$ Al momento de producción de este texto, el Consejo Federal de Educación ha aprobado la definición de los NAP para la Formación General del Ciclo Orientado, el último de la educación obligatoria.

${ }^{23}$ Para ampliar, sobre los NAP, veáse Resolución 247/05; 249/05 y 136/11.
} 
construcción de lo común, partiendo del acuerdo sobre los saberes que se consideran prioritarios, e incluyendo esta definición en un marco de atención a las condiciones pedagógicas que posibilitan el aprendizaje en la escuela, fue la opción curricular elegida... (p.1).

Precisamente, en relación con estas cuestiones, es de destacar la centralidad que han adquirido en las políticas de cambio educativo el conocimiento y las prácticas de enseñanza ${ }^{24}$ como estrategia de inclusión, enmarcada en una perspectiva de trayectoria escolar, en las definiciones federales y jurisdiccionales. Esta centralidad constituye una novedad en las políticas educativas, porque habitualmente la enseñanza es comprendida como un problema didáctico más que como uno de política. Al respecto, Terigi (2006) afirma:

[en el nivel de las políticas educativas] la enseñanza resulta un asunto un poco extraño, porque prevalece un cierto modelo de planeamiento que concibe a la enseñanza como un problema que tiene que ser atendido por otros; que parece creer que la función de la política es proporcionar las condiciones económicas, normativas, materiales, salariales inclusive, para los programas de política educativa. Para estos programas (...), la enseñanza es un problema que tiene que ser solucionado después, por los capacitadores, por los didactas, por los profesores... (p.90).

En definitiva, coincidimos con Terigi (2006) en que la enseñanza es problema central de la política educativa. En este sentido, hemos podido constatar que en esta última década se ha iniciado un proceso argumentado y de acciones concretas -aún no consolidado- que tiende a superar el supuesto del currículum "como el gran ordenador de las prácticas escolares". Esta emergencia del protagonismo de la enseñanza representa, a nuestro juicio, un avance significativo en el diseño y gestión de las políticas en las distintas escalas/territorios que configuran el sistema educativo.

\footnotetext{
24 "Prácticas de enseñanza como prácticas sociales, históricamente determinadas, que se generan en un tiempo y espacio concretos... procesos por los cuales los sujetos se apropian diferencialmente de las cosas, conocimientos, costumbres, usos, espacios, relaciones, reglas de juego..." (Edelstein, 2005, pp. 140-141).
} 
A partir de la sanción de la LEN, el Ministerio de Educación Nacional enfrenta una serie de desafíos que, en una entrevista del año $2009^{25}$, la entonces Subsecretaria de Equidad y Calidad María Inés Vollmer, sintetiza en los siguientes:

- Desarrollar acciones y estrategias conjuntas entre el Gobierno nacional y los gobiernos provinciales y la consecuente concreción de acuerdos federales sobre los aspectos relevantes de la implementación de la Ley de Educación Nacional, brindando asistencia a las jurisdicciones que presentan mayores dificultades para concretarla.

- Asegurar el financiamiento de la educación.

- Fortalecer los sistemas de información y evaluación.

- Incrementar la cobertura del nivel y mejorar las trayectorias escolares de los alumnos, mejorar la calidad de la oferta educativa y fortalecer la gestión institucional de los establecimientos educativos del Nivel Secundario.

En el contexto de las posibilidades de concreción de estos desafíos cobra especial importancia el Plan Nacional de Educación Obligatoria, aprobado por Resolución № 79 del CFE (28-05-09) que ofrece la oportunidad de una construcción conjunta que integre las políticas nacionales, provinciales y locales, las estrategias para enfrentar los desafíos de la educación obligatoria, en sus diferentes ámbitos, niveles y modalidades y la articulación con las intervenciones intersectoriales de otros ministerios y organizaciones sociales.

En cuanto a la Educación Secundaria, el Objetivo estratégico del Plan Trienal 20092011 se focalizó en extender y mejorar la Educación Secundaria en todo el país para garantizar la obligatoriedad con igualdad, inclusión y calidad ${ }^{26}$.

Como una instancia novedosa en la articulación inter-jurisdiccional se conforma la Mesa Federal de Subsecretarios de Educación de las jurisdicciones, coordinada por la Subsecretaría de Equidad y Calidad. Se convoca también a mesas de trabajo por niveles educativos y modalidades y se promueven encuentros intersectoriales. "Estos esfuerzos de coordinación estatal resultan claves para potenciar al máximo la capacidad de planeamiento e implementación de acciones educativas" (Vollmer, 2009).

\footnotetext{
${ }^{25}$ Publicada en Estados de la Educación. Periódico de Políticas Educativas, № 20, del Centro de Implementación de Políticas Públicas para la Equidad y el Crecimiento (CIPPEC).

${ }^{26}$ Para ampliar, respecto del Plan, véase http://portal.educacion.gov.ar/secundaria/plan-nacional-para-laeducacion-secundaria/plan-nacional-de-educacion-obligatoria/ (Recuperado el 15 de enero de 2012).
} 
En cuanto a los desafíos implicados en la transformación de la escuela secundaria, se suceden una serie de Resoluciones del Consejo Federal de Educación que dan cuenta de los Acuerdos que acompañan los cambios previstos (Resolución № 18/2007; 61/2008, 84/2009; 88/2009; 93/2009; 102/2010; 103/2010; 111/2010; 120/2010 y 134/2011) $)^{27}$.

3.1.3. La nueva organización de la Educación Secundaria Orientada a partir de la Ley de Educación Nacional № 26.206

La escuela secundaria se reorganiza en cinco o seis años de escolaridad ${ }^{28}$, distribuidos en dos (2) ciclos: un Ciclo Básico de carácter común a todas las Orientaciones, de dos o tres años de duración, y un Ciclo Orientado -con carácter diversificado- de dos o tres años para las ofertas de Educación Secundaria Orientada, y de tres o cuatro, para las de Educación Secundaria Técnico Profesional (Res. CFE № 47/08) y Artística (Res. CFE № 111/10 y 120/10); la duración de cada ciclo depende de la localización del 7 mo grado.

Tabla N. 01

Organización de la Educación Secundaria LEN N.을.206

\begin{tabular}{|c|c|c|c|}
\hline \multicolumn{4}{|c|}{ Ley de Educación Nacional } \\
\hline \multicolumn{2}{|c|}{ Modelo1 / 7 años -5 años } & \multicolumn{2}{|c|}{ Modelo 2 / 6 años -6 años } \\
\hline Niveles & Años de estudio & Niveles & Años de estudio \\
\hline \multirow{7}{*}{ Primario } & $1 \%$ grado & \multirow{6}{*}{ Primario } & $1^{\circ}$ grado \\
\hline & $2^{\circ}$ grado & & $2 \%$ grado \\
\hline & 3 grado & & 3ㅇ grado \\
\hline & $4^{\circ}$ grado & & $4^{\circ}$ grado \\
\hline & 5o grado & & 5 grado \\
\hline & 6 grado & & 6 grado \\
\hline & $7^{\circ}$ grado & \multirow{7}{*}{ Secundario } & 1ำ año \\
\hline \multirow{6}{*}{ Secundario } & 1ㅇ año & & 2ㅇ año \\
\hline & $2^{\circ}$ año & & 3ำ año \\
\hline & 3ำ año & & $4^{\circ}$ año \\
\hline & $4^{\circ}$ año & & 5o año \\
\hline & 5 año & & 6 año \\
\hline & $\begin{array}{lr}60 & \text { año } \\
\text { Profesiona)! }\end{array}$ & & $\begin{array}{|lr|}7^{0} & \text { año } \\
\text { Profesional) }\end{array}$ \\
\hline
\end{tabular}

Fuente: Elaboración propia.

${ }^{27} \mathrm{Se}$ puede acceder a estos documentos a través del siguiente enlace: http://www.mcye.gov.ar/consejo/resoluciones/cf resoluciones.html (Recuperado el 15 de enero de 2012).

${ }^{28}$ Cabe destacar que la duración de la Educación Secundaria también puede ser de 5 años (Ley 26.206 Art. 134), y en el caso de las escuelas técnicas y agrotécnicas puede llegar a 7años (Artículo 24 de la Ley № 26.058). 
El actual escenario educativo ha quedado configurado por 12 provincias con una estructura de 6 años - 6/7 años (Buenos Aires, Córdoba, Corrientes, Chubut, Entre Ríos, Formosa, La Pampa, San Juan, San Luis, Santa Cruz, Tierra del Fuego y Tucumán) y las restantes 12 jurisdicciones con una estructura de 7 años - 5/6 años (Ciudad de Buenos Aires, Catamarca, Chaco, Jujuy, La Rioja, Mendoza, Misiones, Neuquén, Río Negro, Salta, Santa Fe y Santiago del Estero) (Capellacci, 2011) ${ }^{29}$.

En cuanto a la situación normativa ${ }^{30}$, se puede afirmar que es dispar, dado que solo 11 jurisdicciones cuentan con leyes preexistentes (Ciudad de Buenos Aires, Río Negro) o sancionaron una nueva Ley de Educación (Chaco, Salta, Santiago del Estero, La Rioja, Buenos Aires, Córdoba, Entre Ríos, Chubut, La Pampa), que contemplan los principios de la LEN; otras 9 jurisdicciones han establecido otros tipos de normativas (ya sea resolución, decreto o acuerdo) para definir la estructura académica del sistema, mientras revisan su Ley Provincial (Santa Fe, Misiones, Jujuy, Tierra del Fuego, Corrientes, Formosa, Tucumán, San Juan y San Luis) y 4 jurisdicciones (Neuquén, Santa Cruz, Catamarca y Mendoza) aún no han establecido normativa alguna. Este proceso se está llevando a cabo en forma progresiva y en virtud de la realidad de cada una de las jurisdicciones.

Hoy conviven, según un Informe generado desde la Dirección Nacional de Información y Evaluación de la Calidad Educativa (Capellacci, 2011), 7 tipos de establecimientos con oferta de Nivel Secundario, resultantes de la combinación entre los ciclos educativos y los años de estudio que cada institución ofrece. Algunos de ellos cuentan con una oferta completa, es decir, brindan los Ciclos Básico y Orientado; otros solo con alguno de los Ciclos; en tres casos, aún se considera la estructura anterior a la LEN y en otros, se reconocen combinaciones entre la estructura tradicional, la de la LFE y la de la LEN, a saber:

- Secundaria Completa de 6/7 años $\left(7^{\circ}\right.$ a $\left.12^{\circ} / 13^{\circ}\right)$.

- Secundaria Completa de 5/6 años ( $8^{\circ}$ a $\left.12^{\circ} / 13^{\circ}\right)$.

- Ciclo Básico de Secundaria Independiente de 2 años ( $8^{\circ}$ y 9ำ).

- Ciclo Básico de Secundaria Independiente de 3 años (7ํㅜ a 9ํ).

- EGB3 sin Polimodal (7 a 9ํ).

- Educación Polimodal sin EGB3 (10ำ a 12ํ).

\footnotetext{
${ }^{29}$ No obstante, las provincias de Neuquén, Santa Cruz, Catamarca y Mendoza no han dictaminado aún la normativa provincial que convalide dicha decisión.

${ }^{30}$ Esta información fue tomada de Capellacci, 2011 y actualizada al 31 de diciembre de 2011 por el grupo de investigación.
} 
- EGB3 con Polimodal $\left(7^{\circ}\right.$ a $\left.12^{\circ} / 13^{\circ}\right)$.

- Otros.

Esto se puede explicar en razón del desarrollo de sucesivas definiciones de política educativa y de las posibilidades de acción de cada provincia. Así, es posible encontrar que, en algunas jurisdicciones, coexisten distintos tipos de establecimientos educativos (Capellacci, 2011). En definitiva, el mapa federal de la oferta de Educación Secundaria en los actuales escenarios de transición es heterogéneo en virtud de la diversidad en los niveles de cobertura y de la coexistencia de variedad de configuraciones institucionales en las que convive "lo viejo" con "lo nuevo"31.

El análisis de la normativa y los documentos vigentes en cada una de las jurisdicciones permite establecer que -en todos los casos- la finalidad formativa del primer tramo de la Educación Secundaria (Ciclo Básico) -articulado con la Educación Primaria- es ofrecer a todos los estudiantes oportunidades de continuar apropiándose de los aprendizajes considerados básicos, tanto para su desarrollo personal como para su desempeño cívico y social. Procura atender a las necesidades específicas de los adolescentes y jóvenes, a la continuación de estudios en el Ciclo Orientado, al incremento de los márgenes de autonomía y al desarrollo de proyectos que impliquen procesos intelectuales, prácticos, interactivos y sociales de mayor complejidad que los de la Educación Primaria. Este ciclo es común para todas las orientaciones y modalidades, lo que permite una movilidad directa tanto para aquellos estudiantes que cambien de institución como para los que se muden a otras provincias.

El Ciclo Orientado, en cambio, se propone brindar una formación equilibrada entre lo académico y lo técnico, con valor formativo y social equivalente, de manera tal que profundice las funciones de la Educación Secundaria: la formación del ciudadano, la preparación para proseguir estudios superiores y la formación para el mundo del trabajo. Para ello, deberá ampliar los ámbitos de experiencia de los estudiantes a fin de que puedan perfilar decisiones vinculadas con sus respectivos proyectos de vida, contribuyendo a la visibilización de adolescentes y jóvenes como sujetos de derecho, a su inclusión social y participación política.

Los saberes propuestos en el Ciclo Básico y el Orientado recuperan los campos de formación de presencia generalizada en los diseños curriculares vigentes, que dotan a las

\footnotetext{
${ }^{31}$ Para ampliar, véase Argentina, Ministerio de Educación de la Nación. Dirección Nacional de Información y Evaluación de la Calidad Educativa (DINIECE). Anuarios Estadísticos $2000-2010$. http://diniece.me.gov.ar/index.php?option=com content\&task=category\&sectionid=2\&id=8\&ltemid=19 (Recuperado el 24 de junio de 2012) y Anexo 1, 2, 3 y 4 en Ferreyra, coord., 2012.
} 
ofertas de un equilibrio acorde con las finalidades de la escolaridad secundaria, al mismo tiempo que garantizan su diferenciación y particularidad:

- Campo de Formación General: incluye los saberes acordados socialmente como relevantes e indispensables para garantizar el conocimiento y la interlocución activa de los adolescentes y jóvenes con la realidad, y también los que son pilares de instancias formativas posteriores. En cuanto saber validado colectivamente, la Formación General requiere de un trabajo de enseñanza integrador de las múltiples facetas del conocimiento, que apele a sus diversas herramientas y aplicaciones, que promueva el desarrollo de todos los aspectos de los sujetos, entre sujetos y en situación.

La Formación General constituye el núcleo de formación común de la Educación Secundaria; debe estar presente en todas las propuestas educativas del Nivel e incluirse en los planes de formación de todas y cada una de las Orientaciones y Modalidades. Comienza en el Ciclo Básico $(\mathrm{CB})^{32}$ y se extiende hasta el fin de la obligatoriedad, en el Ciclo Orientado (CO). En este último, la enseñanza en los distintos espacios curriculares que componen la Formación General común se organizará para abordar -toda vez que sea posible- temas y problemáticas relativos a la Orientación y/o Modalidad de que se trate. Esta formación, posibilitará a los estudiantes recorrer las construcciones teóricas y las prácticas de producción de conocimientos propias de la Lengua y la Literatura, la Matemática, las Ciencias Sociales -Historia, Geografía y Economía-, las Ciencias Naturales -Biología, Química y Física-, la Formación Ética y Ciudadana y las Humanidades, la Educación Física, la Educación Tecnológica, la Educación Artística y las Lenguas (clásicas, originarias, regionales, de herencia, extranjeras, de inmigración).

- Campo de Formación Específica: posibilita ampliar la Formación General en el campo de conocimiento propio de la Orientación y/o Modalidad, propiciando una mayor cantidad y profundidad de saberes del área particular de cada oferta, es decir, acrecentando y especificando -en la medida en que cada Orientación o Modalidad lo admita- la enseñanza de las herramientas de trabajo intelectual y los conocimientos de las disciplinas que la estructuran. En este sentido, la organización curricular del Ciclo Orientado prevé -además de los espacios curriculares obligatorios- la inclusión de otros de opción institucional y/o del estudiante a los fines de contextualizar la propuesta formativa.

\footnotetext{
${ }^{32}$ Se adopta como referente curricular a los Núcleos de Aprendizajes Prioritarios del Tercer Ciclo de EGB/Nivel Medio acordados federalmente.
} 
En cuanto a las Orientaciones, las Modalidades y las titulaciones, en el documento “Lineamientos políticos y estratégicos de la Educación Secundaria Obligatoria" (Anexo 1. Resolución CFE $N . \stackrel{0}{84 / 09)}$ se acordaron federalmente las siguientes ofertas para la Educación Secundaria ${ }^{33}$ :

- Educación Secundaria Orientada.

- Educación Secundaria Modalidad Técnico Profesional. ${ }^{34}$

- Educación Secundaria Modalidad Artística. ${ }^{35}$

- Educación Secundaria Modalidad de Educación Permanente de Jóvenes y Adultos. ${ }^{36}$

La Educación Secundaria Orientada debe garantizar una formación que promueva en sus egresados capacidades para la apropiación permanente de nuevos conocimientos, para la inserción en el mundo del trabajo y para la participación en la vida ciudadana. Las diversas ofertas educativas existentes y el acuerdo sobre las futuras, se definen en orden a las diversas Orientaciones identificadas en el cuadro anterior.

En una clara continuidad del proceso de Acuerdos Federales, se construyen participativamente -con representantes (políticos, técnicos y docentes) de todas las jurisdicciones- los Marcos de Referencia para la Educación Secundaria Orientada, que constituyen la manifestación del acuerdo federal acerca de la formación específica para cada una de las Orientaciones y, en este sentido, "son una de las herramientas clave para gestionar la unidad nacional en un contexto de variados procesos y normativas curriculares jurisdiccionales vigentes en el nivel" (Argentina, Ministerio de Educación, Dirección Nacional de Educación Secundaria, 2010, p.20). Estos Marcos permiten ajustar la propuesta formativa en su conjunto, toda vez que constituyen un acuerdo nacional sobre los contenidos que definen cada Orientación y su alcance, en términos de propuesta metodológica y profundización esperada; detallan los saberes que se priorizan para los egresados de la

\footnotetext{
33 También se reconocen otras Modalidades. Véase Resoluciones del CFE № 128/10 (Educación Rural); 164/11 (Educación Hospitalaria y Domiciliaria, documento en discusión); 155/11 (Educación Especial); 127/2010 (Educación en Contextos de Privación de Libertad); 119/10 (Educación Intercultural Bilingüe).

${ }^{34}$ Para ampliar sobre la Educación Secundaria Modalidad Técnico Profesional, véase Resoluciones CFE №261/2006, 13/2007, 14/2007, 15/2007, 18/2007, 31/2007, 47/2008, 84/2009, 93/2009 y 102/2010.

${ }^{35}$ Para ampliar sobre Educación Secundaria Modalidad Artística, véase Resoluciones. CFE NNo 111/10 y 120/10.

${ }^{36}$ Para ampliar sobre la Modalidad de Educación Permanente de Jóvenes y Adultos, véase Resolución del CFE № 118/2010.
} 
Orientación, los criterios de organización curricular específicos y las opciones de formación para la Orientación (Resolución del CFE: 161, 142, 156, 161 y 163/201137).

Transcurridos más de cuatro años de la sanción de la nueva Ley, se observa ${ }^{38}$ que en algunas provincias todavía se organiza el sistema según lo estipulaba la Ley Federal, hoy ya derogada, y en otras se está comenzando con la implementación. Por ejemplo, a fines de 2010, en lo que refiere al Ciclo Básico según lo que establece la nueva Ley, se registran distintos tipos de cambios (normativos, curriculares -estructuras y/o contenidos) en once jurisdicciones: Buenos Aires, Chubut, Córdoba, Entre Ríos, Formosa, La Pampa, La Rioja, Misiones, Río Negro, Salta y Santa Cruz. Con respecto al Ciclo Orientado, cinco jurisdicciones se encuentran en proceso de implementación, con avances diversos: Buenos Aires, Entre Ríos, Córdoba, Misiones y Río Negro ${ }^{39}$.

Iniciábamos nuestra argumentación afirmando que la Educación Media/Secundaria en la Argentina está atravesando un período de transición-resignificación, en el cual conviven factores vinculados a los dos últimos marcos normativos: la Ley Federal de Educación N. ${ }^{\circ}$ 24.195 y la Ley de Educación Nacional N. 26.206. Una mirada comparativa que recupera las principales transformaciones analizadas, permite dar cuenta de las principales líneas de continuidad y cambio que nos interesa destacar.

${ }^{37} \mathrm{Se}$ puede acceder a estos documentos a través del siguiente enlace: http://www.mcye.gov.ar/consejo/resoluciones/cf_resoluciones.html (Recuperado el 15 de enero de 2012).

${ }^{38} \mathrm{La}$ información que se proporciona a continuación fue suministrada por la Dirección Nacional de Gestión Educativa-Dirección de Educación Secundaria y Áreas Curriculares del Ministerio de Educación de la Nación Argentina

39 Para ampliar información respecto de los cambios en las provincias, véase sitios de los Ministerios de Educación de las respectivas jurisdicciones y Anexo 1, 2, 3 y 4 en Ferreyra, coord., 2012. 
Tabla N. -2

La Educación Media/Secundaria entre dos marcos normativos

\begin{tabular}{|c|c|c|c|c|c|}
\hline \multirow[b]{2}{*}{$\begin{array}{l}\text { Aspectos que } \\
\text { se comparan }\end{array}$} & \multicolumn{3}{|c|}{$\begin{array}{l}\text { EDUCACIÓN SECUNDARIA } \\
\text { Ley Federal de Educación }\end{array}$} & \multicolumn{2}{|c|}{$\begin{array}{l}\text { EDUCACIÓN SECUNDARIA } \\
\text { Ley de Educación Nacional }\end{array}$} \\
\hline & $\begin{array}{c}\text { EDUCACIÓN } \\
\text { GENERAL BÁSICA- } \\
\text { TERCER CICLO } \\
\text { (EGB3) } \\
\text { Obligatoria }\end{array}$ & $\begin{array}{l}\text { EDUCACION } \\
\text { POLIMODAL } \\
\text { Postobligatoria }\end{array}$ & $\begin{array}{c}\text { TRAYECTO } \\
\text { TECNICO } \\
\text { PROFESIONAL } \\
\text { Postobligatoria }\end{array}$ & $\begin{array}{l}\text { CICLO BÁSICO } \\
\text { Obligatorio }\end{array}$ & $\begin{array}{c}\text { CICLO ORIENTADO } \\
\text { Obligatorio }\end{array}$ \\
\hline $\begin{array}{c}\text { NECESIDAD } \\
\text { EDUCATIVA } \\
\text { QUE } \\
\text { SATISFACE }\end{array}$ & $\begin{array}{l}\text { - Adquisición de } \\
\text { saberes } \\
\text { elementales y } \\
\text { comunes } \\
\text { imprescindibles } \\
\text { para toda la } \\
\text { población. }\end{array}$ & $\begin{array}{l}\text { - Dominio de } \\
\text { capacidades } \\
\text { intermedias, } \\
\text { deseables según } \\
\text { diversas } \\
\text { realidades y } \\
\text { según cada } \\
\text { opción. }\end{array}$ & $\begin{array}{l}\text { - Logro de } \\
\text { capacitación } \\
\text { profesional } \\
\text { intermedia para el } \\
\text { desempeño en } \\
\text { ámbitos } \\
\text { específicos del } \\
\text { quehacer } \\
\text { productivo. } \\
\end{array}$ & $\begin{array}{l}\text { - Adquisición de } \\
\text { saberes } \\
\text { elementales y } \\
\text { comunes } \\
\text { imprescindibles } \\
\text { para toda la } \\
\text { población. }\end{array}$ & $\begin{array}{l}\text { - Dominio de } \\
\text { capacidades } \\
\text { intermedias, } \\
\text { deseables según } \\
\text { diversas realidades y } \\
\text { según cada } \\
\text { Orientación. }\end{array}$ \\
\hline FUNCIONES & $\begin{array}{l}\text { - Desarrollo } \\
\text { personal y social. } \\
\text { - Propedéutica. }\end{array}$ & $\begin{array}{l}\text { - Ética-ciudadana. } \\
\text { - Propedéutica. } \\
\text { - Preparatoria } \\
\text { para la vida } \\
\text { socio-productiva. }\end{array}$ & $\begin{array}{l}\text { - Profesionalizan- } \\
\text { te. }\end{array}$ & $\begin{array}{l}\text { - Desarrollo } \\
\text { personal y social. } \\
\text { - Propedéutica } \\
\text { (continuidad de } \\
\text { estudios } \\
\text { superiores). }\end{array}$ & $\begin{array}{l}\text { - Ética y ciudadana. } \\
\text { - Propedéutica } \\
\text { (continuidad de } \\
\text { estudios superiores). } \\
\text { - Preparatoria para el } \\
\text { trabajo y la vida. }\end{array}$ \\
\hline FORMACIÓN & $\begin{array}{l}\text { General y } \\
\text { homogeneizante. } \\
\text { - El eje es el } \\
\text { desarrollo de } \\
\text { competencias } \\
\text { básicas. } \\
\text { - Prevé una } \\
\text { iniciación o } \\
\text { aproximación al } \\
\text { mundo del trabajo } \\
\text { y la producción, } \\
\text { sin constituir una } \\
\text { especialización. }\end{array}$ & $\begin{array}{l}\text { General } \\
\text { orientada. } \\
\text { - Contextualiza } \\
\text { y profundiza la } \\
\text { formación en } \\
\text { diferentes } \\
\text { campos del } \\
\text { conocimiento y } \\
\text { del quehacer } \\
\text { socio productivo, } \\
\text { mediante el } \\
\text { desarrollo de } \\
\text { competencias } \\
\text { fundamentales. }\end{array}$ & $\begin{array}{l}\text { - Diversificada y } \\
\text { centrada en el } \\
\text { desarrollo de } \\
\text { competencias } \\
\text { profesionales } \\
\text { vinculadas con } \\
\text { campos } \\
\text { correspondien-tes } \\
\text { a sectores } \\
\text { específicos y } \\
\text { recortados del } \\
\text { mundo } \\
\text { productivo. }\end{array}$ & $\begin{array}{l}\text { General y } \\
\text { homogeneizante. } \\
\text { - El eje es el } \\
\text { desarrollo de } \\
\text { saberes y } \\
\text { capacidades } \\
\text { básicas, con miras } \\
\text { a una formación } \\
\text { ética y ciudadana. } \\
\text { - Prevé una } \\
\text { iniciación o } \\
\text { aproximación al } \\
\text { mundo del trabajo } \\
\text { y la producción. }\end{array}$ & $\begin{array}{l}\text { General y orientada } \\
\text { - Contextualiza y } \\
\text { profundiza la } \\
\text { formación en } \\
\text { diferentes campos } \\
\text { del conocimiento y } \\
\text { del quehacer social } \\
\text { (político, cultural, } \\
\text { económico, científico, } \\
\text { tecnológico, } \\
\text { productivo, etc.). } \\
\text { - Desarrollo de } \\
\text { saberes y } \\
\text { capacidades } \\
\text { fundamentales para } \\
\text { el ejercicio de la } \\
\text { ciudadanía, la } \\
\text { prosecución de } \\
\text { estudios superiores y } \\
\text { la inclusión en el } \\
\text { mundo del trabajo. }\end{array}$ \\
\hline
\end{tabular}

Fuente: Elaboración propia, a partir de Peretti, Ferreyra y Carandino (2001-2003, pp. 343-345) y Ferreyra (coord) (2009, pp. 67-68).

\footnotetext{
${ }^{40}$ A partir del análisis de las Resoluciones y Acuerdos Marco celebrados en la década del '90 en el seno del Consejo Federal de Cultura y Educación.

${ }^{41}$ A partir del análisis de las diferentes Resoluciones del Consejo Federal de Educación y Acuerdos Marco Federales.
} 
Por ello, y en el contexto del debate planteado en este estudio, consideramos relevante una revisión de algunas de las transformaciones que se han suscitado desde el 2001 hasta la fecha. Una mirada comparativa sobre las principales diferencias planteada

\subsection{Cobertura y rendimiento de la oferta de Nivel Secundario}

A sólo 12 años de que la Ley Federal de Educación N²4.195 estableciera la obligatoriedad hasta el primer tramo (2 o 3 años) de la Educación Secundaria, con la nueva Ley de Educación Nacional se incluye formalmente en la legislación de nuestro país a todos los años de escolaridad (5/6 años o 7 años). Este avance legal busca corregir las brechas cuanti cualitativas que se detectan en los diversos indicadores y categorías educativas y aporta un nuevo marco de sentido que favorece la desnaturalización de la desigualdad en el campo de las oportunidades educativas.

No obstante, la mejora en la cobertura respecto de los datos del $2001^{42}$, quedan aún desafíos que enfrentar: escolarizar a aquellos adolescentes y jóvenes que en la actualidad no asisten a la escuela, y garantizar la terminalidad del nivel especialmente a aquellos estudiantes pertenecientes a los sectores sociales que no han sido destinatarios históricos de la Educación Secundaria.

Una aproximación cuantitativa nos permite tener una idea respecto de la situación planteada que se ve potenciada por una serie de condiciones que se están desarrollando en el país; un sostenido crecimiento presupuestario, la mejora en infraestructura y equipamiento, la asignación universal por hijo ${ }^{43}$, clima de diálogo con los sindicatos, leyes aprobadas por unanimidad en el Congreso Nacional son elementos claramente positivos.

\footnotetext{
${ }^{42}$ En el año 2001, la tasa neta de escolarización superaba el 70\% para el total país y se registraba una fluctuación entre el $50 \%$ y el $85 \%$ en virtud de la realidad de las distintas jurisdicciones.

${ }^{43}$ La Asignación Universal por Hijo para Protección Social (Decreto $N^{\circ} 1602 / 09$ ) es un beneficio que le corresponde percibir a las personas desocupadas, que trabajan en el mercado informal o ganan menos del salario mínimo, vital y móvil, cuyos hijos sean menores de 18 años. A través de esta asignación el Estado busca asegurarse de que los niños y adolescentes asistan a la escuela, se realicen controles periódicos de salud y cumplan con el calendario de vacunación obligatorio, ya que éstos son requisitos indispensables para cobrarla (Fuente: $\quad$ http://www.argentina.gob.ar/tramites/1148-asignaci\%C3\%B3n-universal-por-hijo-paraprotecci\%C3\%B3n-social.php). En el mes de noviembre de 2011 se presentó en el Ministerio de Educación el informe denominado "Análisis y evaluación de los aspectos educativos de la Asignación Universal por Hijo $(A \cup H)$ ", que dio cuenta del salto cualitativo que representó, en la escolaridad, la implementación de esta medida que implantó un nuevo piso de ciudadanía social. Se trata de un estudio solicitado a las universidades nacionales de General Sarmiento, La Plata, Misiones, Moreno, Patagonia Austral y Villa María, con el objetivo de evaluar los alcances y efectos logrados con la implantación de la AUH, así como recabar información que permita profundizar sus potencialidades. La investigación recogió información a través de 1200 entrevistas en profundidad en las provincias de Córdoba, San Juan, Formosa, Chaco, Misiones, Corrientes y Buenos Aires.
} 
Con todo, es importante señalar que los datos estadísticos que refieren a las condiciones y realidad de la escolarización en el país no son homogéneos entre las diferentes jurisdicciones, sino dispares en la diversidad del territorio nacional.

A pesar de que los niveles de cobertura escolar (Niveles Básico y Secundario) están entre los más altos de la región, no todos los que ingresan a la escuela la culminan. Actualmente, se debe destacar que casi la totalidad de niños de 6 años se encuentra en la escuela primaria, pero las estadísticas muestran que a pesar de los esfuerzos e intenciones, a los 14 años solo poco más de la mitad ha podido cursar su escolaridad en tiempo y forma, mientras que a los 17 años se encuentran tres grupos casi equivalentes: uno de cada 3 jóvenes está terminando su Secundaria, otro se encuentra cursando con rezago la Educación Secundaria por acumulación de fracaso, y el tercero ya no está en el sistema educativo (Kit y España, en Ferreyra, coord., 2012).

Por su parte, y en cuanto a los resultados de aprendizaje, las evaluaciones realizadas por los Operativos tanto Nacionales -ONE- como internacionales -PISA- revelan que los aprendizajes de los estudiantes son insuficientes. En el 2007, en $2^{\circ}$ año del Nivel Medio se encontraba en esta situación casi el 30\% en Lengua y el 65\% en Matemática. En la misma línea, el Programa Internacional para la Evaluación de los Estudiantes (PISA) de la OCDE de 2009 mostró que el 50\% de los estudiantes de 15 años evaluados no contaba con las habilidades básicas para la comprensión de textos, mientras que más del 60\% se encontraba por debajo del nivel básico en Matemática. La prueba muestra que los resultados de los estudiantes argentinos sufrieron un fuerte descenso en 2009 con respecto a la evaluación de 2000 , donde habían alcanzado 20 puntos más. De los 38 países participantes en ambas pruebas de lectura, la Argentina fue el segundo país que más descendió en sus resultados, aunque cabe mencionar que entre las últimas dos evaluaciones -2006 y 2009- se constata una mejora.

En el ámbito de las evaluaciones nacionales, son un tanto más alentadores los resultados del Primer Operativo Censal de Evaluación de la Calidad Educativa ${ }^{44}$ que en 2010 se aplicó a todos los estudiantes del último año de la escuela secundaria. En tres de las

\footnotetext{
${ }^{44}$ Actualmente los Operativos Nacionales de Evaluación que implementa el Ministerio de Educación de la Nación, en articulación con el conjunto de los ministerios de educación provinciales y el de la Ciudad Autónoma de Buenos Aires, se enmarcan en el Plan de Acciones de Evaluación de Componentes de la Calidad Educativa que fuera aprobado por el Consejo Federal de Educación en la Asamblea celebrada en septiembre de 2010 (Argentina, Ministerio de Educación, 2011, p.5).
} 
áreas evaluadas -Matemática, Ciencias Sociales y Ciencias Naturales-, los resultados revelan que ha disminuido entre 12 y 21 puntos porcentuales, la cantidad de estudiantes con rendimientos bajos. En el caso de Lengua, si bien se observa un aumento de 5 puntos porcentuales de estudiantes con desempeño bajo, respecto del año 2007, esta área es la que presenta menor porcentaje en el nivel bajo, el porcentaje más alto con rendimiento alto $(20,4 \%)$ y la que mayor porcentaje de estudiantes presenta para el conjunto de rendimientos altos y medios $(73,7 \%)^{45}$.

Si bien -como señalan Veleda, Rivas y Mezzadra (2011, p. 135)- estas evaluaciones estandarizadas de ningún modo reflejan "todo lo que ocurre en las aulas", permiten obtener una visión de conjunto, "medir la incidencia de las desigualdades socio-culturales sobre los resultados y relacionar estos resultados con las prácticas, las condiciones de la enseñanza y las políticas en curso (Ravela et al., 2007)”. Estos datos demuestran que déficits de calidad y equidad siguen afectando el itinerario escolar de los jóvenes, e impiden concretar plenamente lo deseado y expresado en las intencionalidades de los marcos legales, aunque se observan indicios de mejora, tal como se desprende de los datos anteriormente analizados.

\subsection{Algunas acciones distintivas de la Educación Secundaria hoy}

Hemos asistido, especialmente en las últimas décadas, a cambios significativos en todo el sistema educativo y en la Educación Secundaria en particular. Las profundas transformaciones políticas, económicas, sociales y culturales en el orden mundial, regional y local impactan en el ámbito educativo en todos sus niveles.

Acompañando el nuevo marco legal, se han realizado algunas acciones que intentan fortalecer una Educación Secundaria atravesada por problemáticas tales como crecimiento de la pobreza, nuevas incertidumbres ante economías "globales y flexibles" con "organizaciones flexibles y cambiantes" en un mundo donde, entre otras cosas, la "compresión del tiempo y el espacio" modifica los escenarios presentes y futuros (Hargreaves, 1996). A manera de ejemplo, describiremos algunas resoluciones, estrategias, planes y/o proyectos de los últimos años que, como parte de las políticas educativas,

\footnotetext{
${ }^{45}$ Argentina, Ministerio de Educación, 2011. El Informe completo puede consultarse en http://diniece.me.gov.ar/images/stories/diniece/evaluacion educativa/nacionales/resultados/Resultados\%20Censo \%200NE\%202010.pdf (Recuperado el 15 de enero de 2012).
} 
intentan regular y generar modificaciones en pos de la mejora de la Educación Secundaria en nuestro país.

En el año 2009, el Consejo Federal de Educación (CFE), conformado por las máximas autoridades educativas nacionales y provinciales, acordó un Plan Nacional de Educación Obligatoria (Resolución CFE $N^{\circ} 79 / 09$ ) y un conjunto de lineamientos para la Educación Secundaria:

- La Resolución CFE 84/09 -Lineamientos Políticos y Estratégicos de la Educación Secundaria Obligatoria- define que las políticas educativas deben garantizar el derecho a la educación, la inclusión a partir del efectivo acceso, la continuidad escolar y el egreso, así como condiciones pedagógicas y materiales para hacer efectivo el tránsito por el nivel obligatorio. Además, propone, entre otras estrategias, "acordar federalmente la revisión de toda regulación y de aquellas prácticas que comprometan el cumplimiento de la obligatoriedad de la educación secundaria".

- La Resolución CFE 88/09 - Institucionalidad y Fortalecimiento de la Educación Secundaria Obligatoria; Planes Jurisdiccionales y Planes de Mejora Institucionalincluye diversas estrategias de apoyo a las escuelas para promover su fortalecimiento como institución, la renovación del vínculo con las familias, los organismos del Estado y las organizaciones comunitarias. Para ello, en dicha Resolución se expresa claramente que el sistema educativo en su conjunto (gobiernos educativos, institutos superiores de formación docente, equipos directivos y docentes de escuelas secundarias, estudiantes y comunidades) deberá abocarse al diseño e implementación de procesos de mejora. Se señala que los instrumentos que constituyen apoyos básicos de los procesos de institucionalización y fortalecimiento de la Educación Secundaria son dos: 1) los Planes Jurisdiccionales de Educación Secundaria, con el propósito de ordenar, priorizar y promover con la racionalidad necesaria las múltiples decisiones y gestiones que implica en cada provincia la implementación de la obligatoriedad de la educación secundaria y 2) los Planes de Mejora Institucionales, cuyo ámbito de definición y acción alcanza a todas las escuelas secundarias del país, de enseñanza común y modalizadas, según lo establece la Ley de Educación Nacional, contemplando los Ciclos Básicos Rurales ${ }^{46}$.

\footnotetext{
${ }^{46}$ En marzo de 2011, desde el Ministerio de Educación de la Nación, se editó el Documento 1 "Diseño e implementación del Plan de Mejora Institucional" en el que se enfatiza: "Los Planes de Mejora son una
} 
- En la Resolución CFE 93/09, se establece que durante el año 2010 las jurisdicciones comenzarían a implementar los procesos de revisión, reformulación y/o reelaboración de las regulaciones sobre a) evaluación, acreditación y promoción de los estudiantes; b) acompañamientos específicos de las trayectorias escolares; c) condiciones de ingreso, permanencia, movilidad y egreso de los estudiantes y d) convivencia escolar, fijando a su vez que, a partir del ciclo lectivo 2011, las jurisdicciones arbitrarían los medios necesarios para iniciar la aplicación gradual de los regímenes académicos de carácter jurisdiccional.

- Mediante la Resolución CFE № 130/10 se definen estrategias diferenciadas para lograr la inclusión educativa de adolescentes y jóvenes, menores de 18 años, que no están incorporados al sistema educativo o que tienen una situación irregular, con el fin de "garantizar el derecho de todos a una educación secundaria con conocimientos y valores relevantes" (Anexo I). Entre las estrategias que se señalan, se destacan: a) Regularización del trayecto escolar, para aquellos estudiantes del Ciclo Básico que presentan inasistencias por períodos prolongados, repitencia reiterada o con ingresos tardíos al Nivel Secundario; b) Unidades Articuladas de Educación Secundaria, que se constituyen con arraigo en el contexto socio cultural, integrando el desarrollo de las capacidades propias de la formación básica con la capacitación laboral y/o la formación artística, pero estimulando también la continuidad de los estudios en el Ciclo Orientado; c) Estrategias orientadas a incorporar y garantizar la escolarización de estudiantes en el Ciclo Básico y Orientado, para espacios sociales rurales aislados.

Desde el nivel central, se han diseñado Programas que apoyan el desarrollo de la Educación Secundaria en las jurisdicciones: Conectar Igualdad (inclusión digital educativa), Mejoramiento de la enseñanza de las ciencias, Promoción de la lectura, Educación Sexual Integral, Articulación, Construcción de ciudadanía en la escuela, Convivencia escolar, Mediación escolar, Educación solidaria, Educación y Memoria, Escuela y Medios, Tecnologías de la Información y la Comunicación, Consumo problemático de drogas, Observatorio argentino de violencia en la escuela, Canal Encuentro, Portal Educativo del

oportunidad para ampliar y profundizar esas propuestas, así como para evaluar lo transitado hasta el momento, revisando y reformulando las iniciativas en aquellos casos en que se considere necesario (...) se trata de una oportunidad para poner a prueba aquellas estrategias organizativas y curriculares con fuerte incidencia sobre las trayectorias escolares que, por no contar con el apoyo material y simbólico necesario, se fueron dejando de lado. Si así fuera, el Plan de Mejora Institucional será una buena ocasión para revisar y reorientar el Proyecto Institucional Educativo, en pos de fortalecerlo" (pp. 12-13). 
Estado Argentino, Recursos educativos y publicaciones, Provisión de material didáctico, Políticas socioeducativas (Becas, Movilidad, Apoyo para el desarrollo de propuestas socioeducativas, Provisión de libros, Turismo educativo y recreación, Centro de Actividades Juveniles, Prevención del abandono escolar, entre otros), Infraestructura y Equipamiento ${ }^{47}$.

En línea con estas acciones que el Ministerio de Educación Nacional y los Organismos de Educación Jurisdiccionales se encuentran desarrollando, tendientes a garantizar la calidad educativa, y atendiendo al debido resguardo de la unidad del Sistema Educativo Nacional, en el marco del proceso de aplicación de la Ley de Educación Nacional (a lo cual las autoridades educativas nacionales y jurisdiccionales están obligadas en virtud de los Acuerdos Federales), cobra especial relevancia la Resolución Ministerial №1883 de diciembre de 2010. Mediante ella, haciendo uso de las atribuciones que le confiere la ley ${ }^{48} y$ teniendo en cuenta el Decreto del Poder Ejecutivo $N^{\circ} 144 / 08$, Resoluciones Ministeriales ${ }^{49}$ previas y las correspondiente emanadas del $\mathrm{CFE}^{50}$, el Ministro de Educación de la Nación resuelve implementar a partir del ciclo lectivo 2011 las recomendaciones establecidas para la movilidad estudiantil en la educación obligatoria.

Estas recomendaciones -enmarcadas en el reconocimiento de la responsabilidad de las escuelas por los procesos y los resultados de los aprendizajes de todos los estudiantesorientan y avalan la adopción de medidas que posibiliten la continuidad de los estudios de los que cambian de orientación, modalidad, institución y/o jurisdicción educativa en el curso

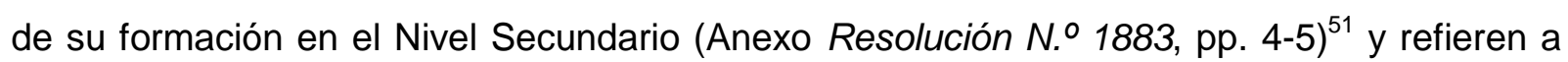
equivalencias, adquisición y acreditación de saberes en situaciones de movilidad, alternativas institucionales para la adquisición y acreditación de saberes y movilidad en el MERCOSUR educativo.

Si bien no agotamos aquí el desarrollo de todos los planes, programas, proyectos y otras acciones que se están llevando a cabo para intentar revertir algunas problemáticas

\footnotetext{
${ }^{47}$ Para ampliar sobre la caracterización de dichos Programas se puede acceder al Portal del Ministerio de Educación de la Nación Argentina - http://portal.educacion.gov.ar/ -, como así también a los sitios web de los Ministerios, Consejos y/o Direcciones Generales de Nivel/de Escuelas de las distintas jurisdicciones.

${ }^{48} \mathrm{El}$ artículo 115, inciso g) de la Ley de Educación 26.206 prevé que el Poder Ejecutivo Nacional, a través del Ministerio de Educación, tendrá como función dictar normas generales sobre equivalencias de planes de estudios y diseños curriculares de las jurisdicciones, de acuerdo con lo establecido en el artículo 85 de dicha ley y otorgar validez nacional a los títulos y certificaciones de estudios.

49 Resolución Ministerial N $1019 / 09$ y $1120 / 10$.

${ }^{50}$ Resoluciones № 18/07, 47/08, 59/08, 79/09, 84/09, 88/09, 93/09 y 102/10.

${ }^{51} \mathrm{Se}$ puede acceder a dicha Resolución y a su Anexo en http://portal.educacion.gov.ar/secundaria/files/2010/03/RESOLUCION-1883-Recomendaciones1.pdf
} 
cruciales y distintivas de la Educación Secundaria, es posible advertir que si bien se están realizando esfuerzos de gran envergadura, aún persisten serias dificultades para lograr su transformación, para "refundarla" -como expresa Claudia Romero (2009)-, pues las "soluciones parciales pueden ser fagocitadas por una matriz institucional fragmentaria y academicista" (p. 9). Por ejemplo, es conocido por todos que la escolarización secundaria ha aumentado notablemente en los últimos años, pero que perviven los índices de fracaso escolar, repitencia y abandono, a la vez que han aparecido fenómenos denominados de "marginación por inclusión" que nos hablan de un estudiante que permanece en el sistema pero sin garantías de aprendizaje. Sin embargo, aun cuando perduran la fragmentación y las dificultades para lograr una mayor inclusión con equidad, no podemos negar que estos programas y planes contribuyen a repensar una escuela secundaria diferente y a enfrentar el desafío de la transformación.

\section{Cierre y reflexiones finales}

Actualmente, se puede afirmar que, si bien hay continuidad en las líneas de trabajo, la situación en el país es diversa, pero el denominador común es un modelo de trabajo participativo. Hay jurisdicciones que ya han implementado toda la secundaria, otras están diseñado Ciclo Básico y Ciclo Orientado; otras, solo Ciclo Básico; algunas recién están iniciando el proceso. Cabe destacar, además, que se han propuesto múltiples alternativas de desarrollo curricular.

En esta línea, consideramos que las jurisdicciones que han implementado el Ciclo Básico u Orientado en estos años se verán en la necesidad de revisar sus diseños a la luz de los Acuerdos y Marcos Federales recientemente aprobados (2011) a los fines de efectuar los ajustes que consideren pertinentes, para evitar la réplica de algunos errores cometidos en el proceso de implementación de la Ley Federal de Educación en otras épocas.

Queda pendiente la homologación de títulos para las 10 Orientaciones y avanzar hacia la calidad educativa. Es imprescindible avanzar en la operacionalización de los NAP del Tercer Ciclo/Ciclo Básico y los del Ciclo Orientado, así como profundizar la articulación de las ofertas de Educación Secundaria Orientada y de las Modalidades, para evitar fragmentaciones.

Esta diversidad de situaciones, así como las demás que hemos indagado, dan cuenta de los cambios significativos que se han producido y se siguen produciendo en la Educación 
Secundaria en nuestro país. Algunos de ellos son propios del sistema y del nivel y otros, más generales, afectan a todos los sujetos y las instituciones en este complejo presente.

UNICEF ARGENTINA señala que el nudo más crítico del sistema escolar es la educación de adolescentes y jóvenes, y agrega:

El acceso y la retención con calidad [de los adolescentes y jóvenes] exigen propuestas innovadoras y escuelas y profesores formados en nuevas áreas del conocimiento, teniendo en cuenta las nuevas problemáticas, lenguajes y culturas, así como los cambios en las formas de acceso a la información y las necesidades de participación en una sociedad exigente, desigual y cambiante ${ }^{52}$.

Estos desafíos, sumados a los ya vislumbrados, operan a modo de notas sobre temas pendientes, tanto en la construcción de problemas -cuya potencia permita una mirada más profunda, comprensiva y crítica de la Educación Secundaria- como en la exploración de propuestas que contribuyan a garantizar la educación como derecho y la obligatoriedad del Nivel.

\section{Referencias}

Albergucci, Roberto. (1996). ¿Qué significa detener o transformar la transformación educativa? Novedades Educativas, 8(72), 20-39.

Argentina, Ministerio de Educación, Ciencia y Tecnología. Áreas Curriculares. (2007). Políticas de Enseñanza y Desarrollo Curricular. Plan De Trabajo 2007. Buenos Aires: Autor.

Argentina, Ministerio de Educación, Ciencia y Tecnología. DINIECE. (2007). La obligatoriedad de la educación secundaria en Argentina. Deudas pendientes y nuevos desafíos. Buenos Aires: Autor.

Argentina, Ministerio de Educación, Ciencia y Tecnología. DINIECE. (2010-2012). Anuarios. Buenos Aires: Autor.

Argentina, Ministerio de Educación. (2011). Operativo Nacional de Evaluación 2010 CENSO DE FINALIZACIÓN DE LA EDUCACIÓN SECUNDARIA. Informe de Resultados. Buenos Aires: Autor. Recuperado de http://diniece.me.gov.ar/images/stories/diniece/evaluacion educativa/nacionales/resulta dos/Resultados\%20Censo\%200NE\%202010.pdf

\footnotetext{
${ }^{52}$ Fuente: Portal UNICEF Argentina. http://www.unicef.org/argentina/spanish/children 11131.htm
} 
Argentina, Ministerio de Educación. DINIECE. (2010). Trayectorias socio-educativas de jóvenes y adultos y sus experiencias con la escuela media. Buenos Aires: Autor.

Argentina, Ministerio de Educación. Dirección Nacional de Educación Secundaria. (2010). Secundaria en el Bicentenario. Revista Digital de la Dirección de Educación Secundaria, (1). Buenos Aires: Autor.

Ávila Paz, María Cecilia, Bonetti, Olga y Chiavaro, Sandra. (2003). La política educativa argentina de los ' 90 como parte del proyecto de reforma del estado, en el marco de la mundialización. En Pedro Baquero Lazcano y otros. La Mundialización en la realidad argentina II (pp. 81-111). Córdoba, Argentina: El Copista.

Braslavsky, Cecilia (org). (2001). La educación secundaria ¿Cambio o inmutabilidad? Análisis y debate de procesos europeos y latinoamericanos contemporáneos. Buenos Aires: IIPE - Santillana.

Capellacci, Inés (coord.). (2011). Diversidad de la oferta de Nivel Secundario y desigualdad educativa. Serie informes de Investigación. Buenos Aires: Ministerio de Educación de la Nación. DINIECE.

Edelstein, Gloria. (2005). Enseñanza, políticas de escolarización y construcción didáctica. En Frigerio, G. y Diker, G. Educar: ese acto político (pp.139-152). Buenos Aires: Del Estante.

Ferreyra, Horacio. (2006). Transformación de la educación media en la Argentina. Tensiones y conflictos en el diseño e implementación en la provincia de Córdoba. Córdoba, Argentina: Editorial Universidad Católica de Córdoba.

Ferreyra, Horacio (coord.). (2012). Entramados, análisis y propuestas para el debate. Aproximaciones a la Educación Secundaria en la Argentina (2000-2010). Informe Grupo de Estudio sobre Educación Secundaria Facultad de Educación Universidad Católica de Córdoba (UCC). Córdoba, Argentina: UCC-Comunicarte.

Ferreyra, Horacio (coord); Cingolani, Mabel; Eberle, María Jacinta, Gallo, Griselda; Larrovere, Crescencia; Luque, Mónica, Pasut, Marta; Peretti, Gabriela y Rimondino, Rubén. (2009). Educación Secundaria Argentina. Propuestas para superar el diagnóstico y avanzar hacia su transformación. Buenos Aires: Ediciones Novedades Educativas y Academia Nacional de Educación.

Ferreyra, Horacio; Peretti, Gabriela; Carandino, Edgardo; Eberle, María Jacinta; Provinciali, Delia; Rimondino, Rubén y Salgueiro, Alejandra. (2006). Educación Media en Argentina: ¿El Problema de los Problemas? Revista Iberoamericana de Educación, 39 (4). Recuperado de http://www.rieoei.org/1498.htm

Gallart, María Antonia. (2006). La construcción social de la escuela media. Una aproximación institucional. Buenos Aires: Stella/La Crujía. 
Hargreaves, Andy. (1996). Profesorado, Cultura y Posmodernidad. Cambian los tiempos, cambia el profesorado. Madrid: Morata.

Kit, Irene y España, Sergio. (2012). La promesa pendiente de la educación como justicia social. En Horacio Ferreyra (coord), Entramados, análisis y propuestas para el debate. Aproximaciones a la Educación Secundaria en la Argentina (2000-2010). Informe Grupo de Estudio sobre Educación Secundaria Facultad de Educación Universidad Católica de Córdoba (UCC). Córdoba, Argentina: UCC-Comunicarte.

Romero, Claudia. (2009). La mejora en la escuela secundaria. En Romero, C. (comp.) Claves para mejorar la escuela secundaria. La gestión, la enseñanza y los nuevos actores (pp.9-16). Buenos Aires: Novedades Educativas.

Sañudo Guerra, Lya. (2007). De la incorporación a la inclusión. Un estudio de la cultura educativa. Guadalajara, México: Conacyt.

Terigi, Flavio. (2006). La educación como práctica política. Diálogos Pedagógicos, IV (7), 89105.

Veleda, Cecilia; Rivas, Axel y Mezzadra, Florencia. (2011). La construcción de la justicia educativa. Criterios de redistribución y reconocimiento para la educación argentina. Buenos Aires: CIPPEC y UNICEF. Recuperado de http://www.unicef.org/argentina/spanish/CIPPEC JusticiaEducativa.pdf

Vollmer, María Inés. (2009). Entrevista. Estados de la Educación. Periódico de Políticas Educativas, (20). Recuperado http://www.cippec.org/estados/n20/eeducacion n20.htm\#entrevistado 